\title{
UCRL-TR-207195
}

LAW RENCE LIVERMORE N A T IO N A L LABORATORY
Dimensional Measurements of Three Tubes by Computed Tomography

D. J. Schneberk, H. E. Martz, Jr., W. D. Brown

October 13, 2004 
This document was prepared as an account of work sponsored by an agency of the United States Government. Neither the United States Government nor the University of California nor any of their employees, makes any warranty, express or implied, or assumes any legal liability or responsibility for the accuracy, completeness, or usefulness of any information, apparatus, product, or process disclosed, or represents that its use would not infringe privately owned rights. Reference herein to any specific commercial product, process, or service by trade name, trademark, manufacturer, or otherwise, does not necessarily constitute or imply its endorsement, recommendation, or favoring by the United States Government or the University of California. The views and opinions of authors expressed herein do not necessarily state or reflect those of the United States Government or the University of California, and shall not be used for advertising or product endorsement purposes.

This work was performed under the auspices of the U.S. Department of Energy by University of California, Lawrence Livermore National Laboratory under Contract W-7405-Eng-48. 


\section{Dimensional Measurements of Three Tubes by Computed Tomography ${ }^{1}$ \\ Daniel J. Schneberk, Harry E. Martz, Jr. and William D. Brown \\ UCRL-\#, Lawrence Livermore National Laboratory, Livermore, CA 94550}

Low density polyethylene (LDPE), copper $(\mathrm{Cu})$, and gold $(\mathrm{Au})$ tubes were scanned on KCAT to identify and evaluate the impact of phase effects on quantitative object recovery. These tubes are phantoms for high energy density capsules.[Logan, et al. 2004] Digital radiographs for each tube are shown in Figure 1. The LDPE tube was scanned at $60 \mathrm{kV}$, while the $\mathrm{Cu}$ and the Au tubes were scanned at $140 \mathrm{kV}$. All tubes were scanned at a magnification of 3, with approximately $100-\mathrm{mm}$ distance between the exit plane of the tube and the scintillator. Notice the prominence of the outer bright and inner dark edges for the LDPE tube DR, and their absence from the $\mathrm{Cu}$ and $\mathrm{Au}$ tube DRs. The bright and dark edges are a result of change in phase of the $\mathrm{x}$-rays. The $\mathrm{x}$-ray fluence is partly attenuated and partly refracted. The location near the outer edge of the tube appears to be more attenuating since those $\mathrm{x}$-rays have refracted to locations just outside the tube. Alternatively, the added counts from the refraction result in intensities that are greater than the incident intensity effectively representing a "negative attenuation". This results in more counts in that location than in the incident intensity image violating the "positivedefinite" requirement for standard CT reconstruction methodologies. One aspect of our CT processing techniques remove some of this signal on the outside of the object. The goal of this paper is to evaluate the accuracy of our dimensional measurement methods for mesoscale object inspection.

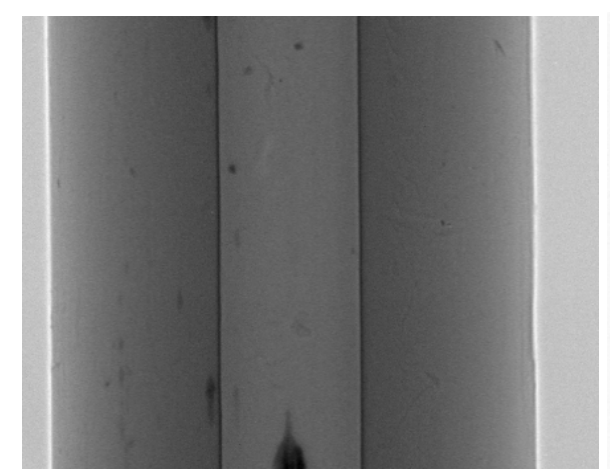

Low Density Polyethylene Tube

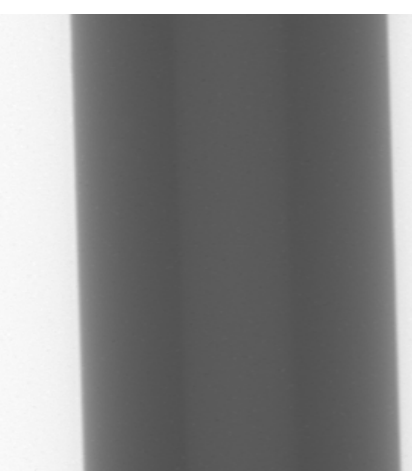

Copper Tube

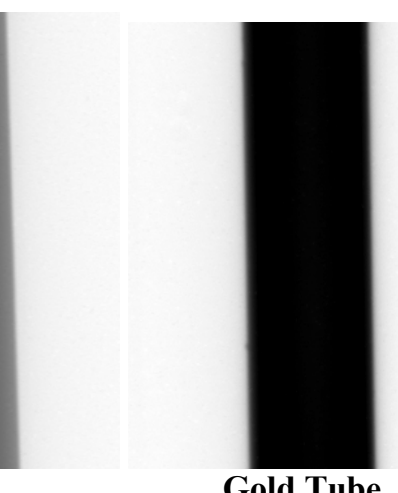

Gold Tube

Figure 1 - Transmission digital radiographs of tube test objects.

CT cross sectional images of the three tubes are shown in Figure 2. Notice the bright edges for the LDPE tube and the deviation from a circle on the inner edges of the $\mathrm{Cu}$ and $\mathrm{Au}$ tubes. Dimensional measurements of the tubes are summarized in Table 1. For the LDPE tube the outer-diameter micrometer ${ }^{2}$ and CT measurements ${ }^{3}$ are, within uncertainty, the same, however they are about $2 \%$ lower than the manufacturer provided specification ${ }^{4}$. The wall thickness (see Appendix) of the LDPE tube from the CT data (Figure 3) was determined to be $0.389 \pm 0.009$. If the manufacturer specification for the wall thickness is correct, it appears the bright edges in the CT LDPE data result in an overestimate of the wall thickness by at least $30 \mu \mathrm{m}$. It is clear that if we do not account for the phase effects the dimensional measurements can be off by a considerable amount, in this case $39 \mu \mathrm{m}$ on average, when we need $\mu \mathrm{m}$ accuracies.

\footnotetext{
${ }^{1}$ This work was performed under the auspices of the U.S. Department of Energy by the University of California, Lawrence Livermore National Laboratory under Contract No. W-7405-Eng-48.

${ }^{2}$ The micrometer measurements were performed by two people. The average of these two measurements with uncertainty are quoted in Table 1.

${ }^{3}$ For all the tubes the outer-diameter CT measurements were determined by the average of two methods. One method was the average of seven estimates of the diameter from line outs through the center. The other method was to determine the best fit circle to the outer boundary.

${ }^{4}$ All three tubes were purchased from Goodfellow http://www.goodfellow.com/csp/active/gfwelcome.csp.

There are no uncertainties in the manufacturer outer-diameters or wall thicknesses specified.
} 
For the $\mathrm{Cu}$ tube, the outer-diameter micrometer measurements resulted in $0.625 \pm 0.007 \mathrm{~mm}$ and agree very well with the measured CT data (Figure 4) outer diameter value of $0.625 \pm 0.002 \mathrm{~mm}$. These measured values are $0.125 \mathrm{~mm}$ or $20 \%$ less than the manufacturer specified value of $0.75 \mathrm{~mm}$. The measured CT wall thickness for the $\mathrm{Cu}$ tube is $0.197 \pm 0.008 \mathrm{~mm}$, which is at least $0.015 \mathrm{~mm}$ less than the manufacturer specified thickness of 0.22 . It may be that the actual wall thickness is $12 \%$ smaller than the manufacturer specified value given the $20 \%$ smaller outer-diameter micrometer and CT measurements of the tube relative to the manufacturer specified value. It is useful to note the variation in the inner wall of the $\mathrm{Cu}$ tube as revealed by the $\mathrm{CT}$ data in Figure 2.

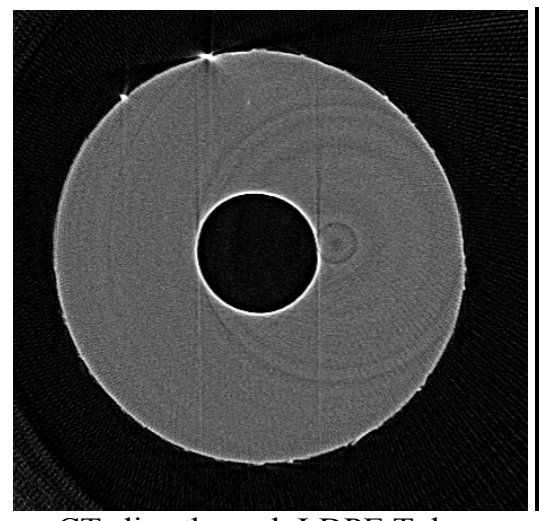

CT slice through LDPE Tube

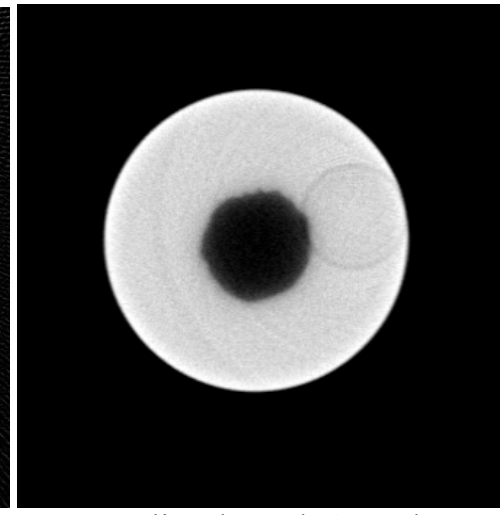

CT Slice through $\mathrm{Cu}$ Tube

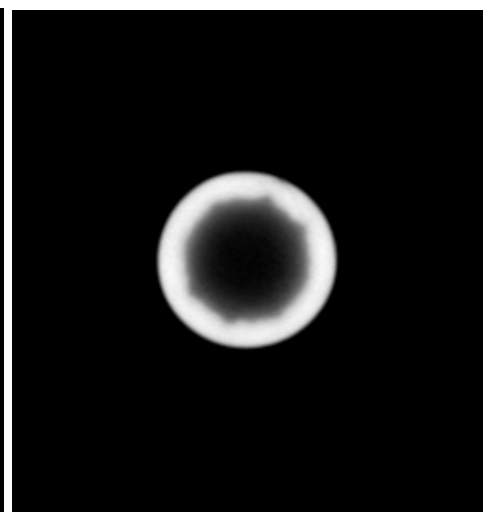

CT Slice through Au Tube

Figure 2 - CT cross sections of the three tubes. Note the bright edges for the LDPE tube and the deviation from a circle on the inner edges of the $\mathrm{Cu}$ and Au tubes.

For the $\mathrm{Au}$ tube, as with the $\mathrm{Cu}$ tube, the micrometer and $\mathrm{CT}$ measured outer-diameter measurements are in good agreement. However these values are on average $10 \%$ lower than the manufacture specified diameter of the Au tube as shown in Table 1. The mean wall thickness of the Au tube was measured by CT (see Figure 5) to be $0.042 \pm 0.002$ and is $19 \%$ less than the manufacturer specified value of $0.050 \mathrm{~mm}$. Furthermore it is useful to note the variation in the inner wall of the Au tube as revealed by the CT data in Figure 2. Given this you wonder how the manufacturer actually determines the wall thickness.

Table 1. Comparison of tube specifications from manufacturer and resulting measured values.

\begin{tabular}{c||c|c|c||c|c||c} 
Tube & $\begin{array}{c}\text { Goodfellow } \\
\text { specified outside } \\
\text { diameter } \\
\mathbf{( m m})\end{array}$ & $\begin{array}{c}\text { Micrometer } \\
\text { measured* } \\
\text { outside diameter } \\
\mathbf{( m m}\end{array}$ & $\begin{array}{c}\text { CT measured } \\
\text { outside } \\
\text { diameter } \\
\mathbf{( m m}\end{array}$ & $\begin{array}{c}\text { Goodfellow } \\
\text { specified } \\
\text { wall thick } \\
\mathbf{( m m})\end{array}$ & $\begin{array}{c}\text { Mean CT } \\
\text { measured } \\
\text { wall thickness } \\
\mathbf{( m m})\end{array}$ & $\begin{array}{c}\text { Goodfellow } \\
\text { Density } \\
\left(\mathbf{g} / \mathbf{c m}^{\mathbf{3}} \mathbf{)}\right.\end{array}$ \\
\hline \hline $\mathbf{L D P E}^{\Delta}$ & 1.100 & $1.075 \pm 0.007$ & $1.08 \pm 0.01$ & 0.350 & $0.389 \pm 0.009$ & 0.92 \\
\hline $\mathbf{C u}$ & 0.750 & $0.625 \pm 0.007$ & $0.625 \pm 0.002$ & 0.220 & $0.197 \pm 0.008$ & 8.96 \\
\hline $\mathbf{A u}$ & 0.300 & $0.270 \pm 0.007^{+}$ & $0.28 \pm 0.02$ & 0.050 & $0.042 \pm 0.002$ & 19.32 \\
\hline \hline
\end{tabular}

${ }^{\Delta}$ Low Density PolyEthylene

* The micrometer measurements were performed by two people. The average of these two measurements with uncertainty are quoted.

${ }^{+}$The two Au tube micrometer measurements were the same value; we choose to use the average of the LDPE and Cu tubes uncertainty as the Au tube uncertainty value. 
LDPE Rod Wall Thickness

(Blue - CT measurement, Purple-Goodfellow specified, Yellow - Avg. CT measurement)

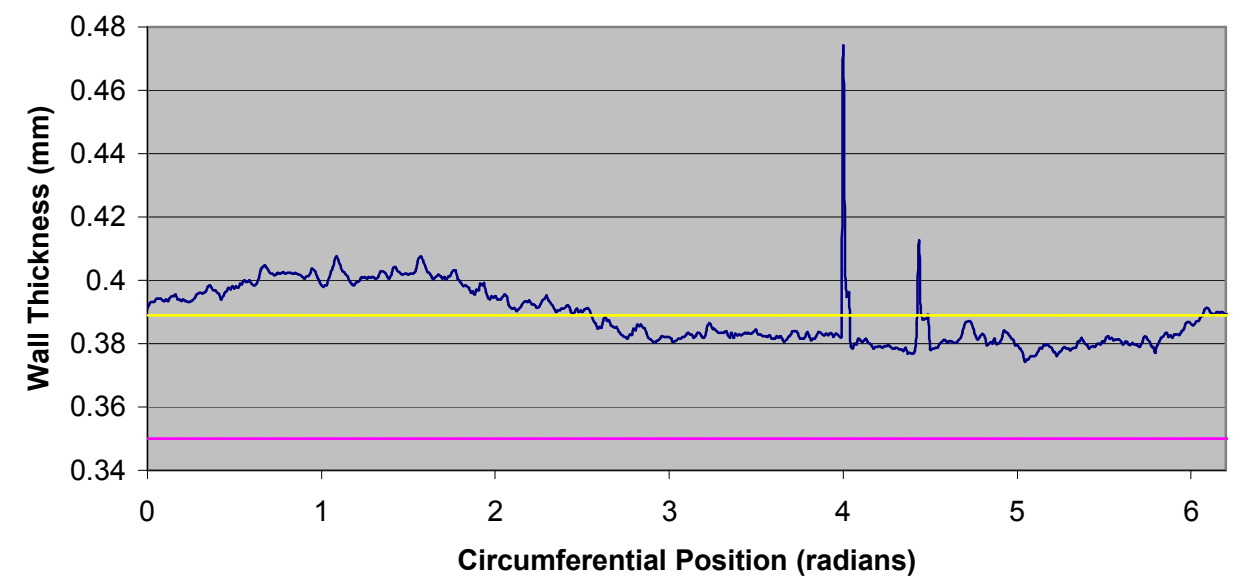

Figure 3 - Low density polyethylene tube results of the CT wall thickness measurements (blue) and average value (yellow) compared to the manufacturer specified wall thickness (purple). The two outliers (peaks) are due to the extra material on the outside edge of the LDPE tube shown as white spots in Figure 2 at 10-12 o'clock. Overall the results reveal that the inner and outer walls (circles) are not concentric.

\section{Cu Rod Wall Thickness Results \\ (Blue - CT measurement, Purple - Goodfellow specified, Yellow - average of CT measurement)}

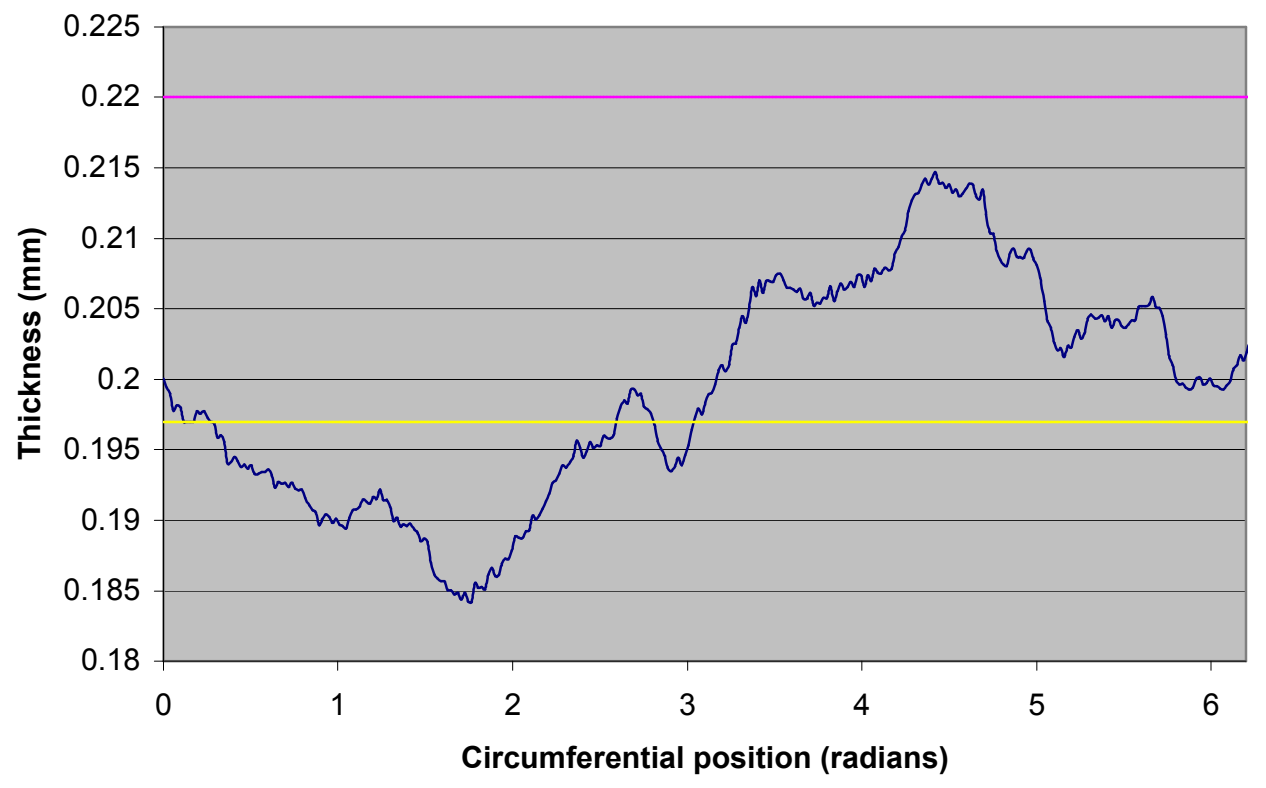

Figure 4 - Copper tube results of the CT wall thickness measurements (blue) and average value (yellow) compared to the Goodfellow specified wall thickness (purple). Overall the results reveal that the inner and outer walls (circles) are not concentric and have a perturbation on the inner wall as shown in Figure 2 for the Cu-tube CT slice. 


\section{Wall Thickness of Gold Cylinder \\ (Blue - CT measurement, Purple-Goodfellow specified, Yellow - Avg of CT measurements )}

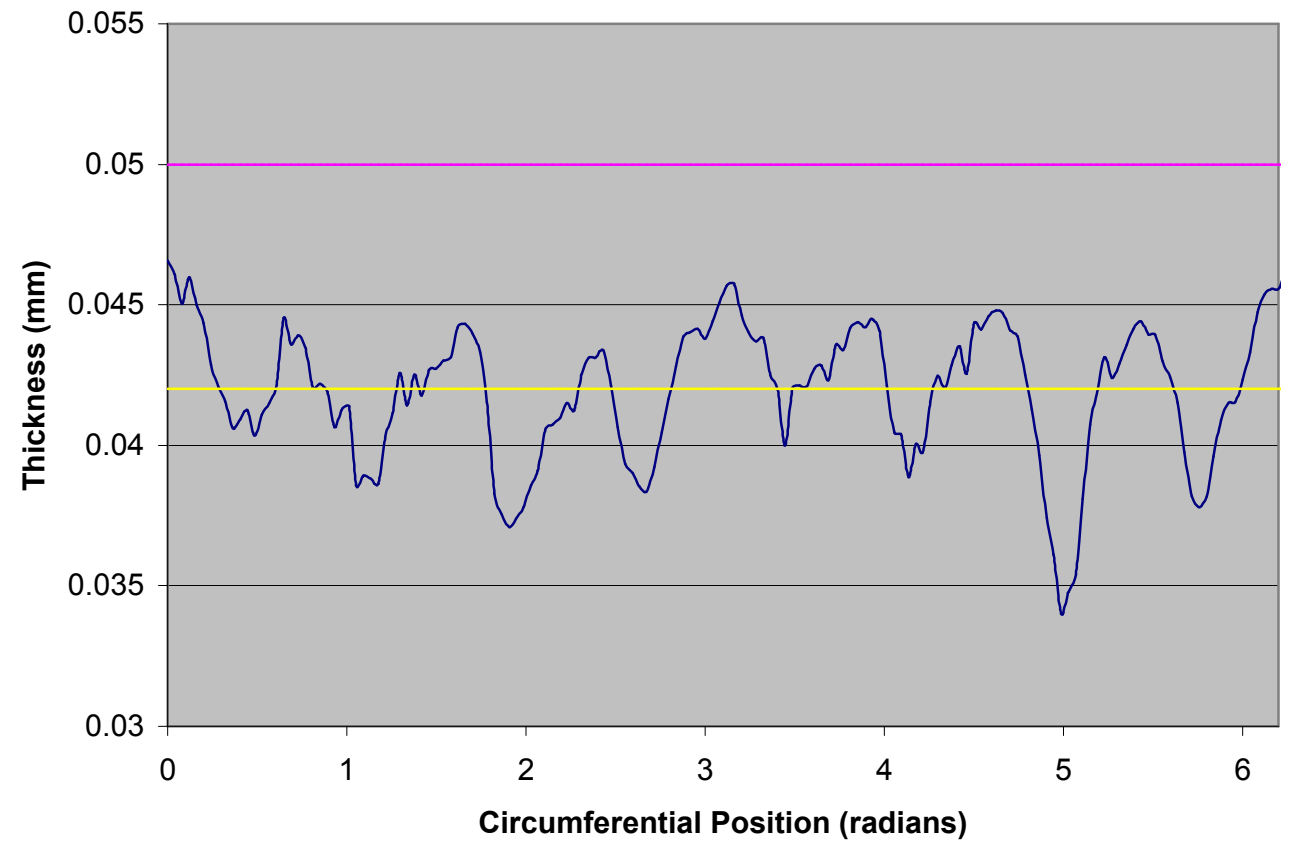

Figure 5 - Gold tube results of the CT wall thickness measurements (blue) and average value (yellow) compared to the manufacturer specification wall thickness (purple). Overall the results reveal that the inner and outer walls (circles) are concentric but have a perturbation on the inner wall as shown in Figure 2 for the Au tube CT slice.

From the LDPE tube CT results the presence of phase effects impacts our ability to quantitatively measure features in mesoscale objects. The LDPE tube includes phase effects on both the inner and outer edges. For this tube, while the CT measurements of the outer diameter are within uncertainty of the micrometer measured value but differ from the manufacturer specified value by $25 \mu \mathrm{m}$ and the wall thickness is over estimated by a considerable amount, at least $30 \mu \mathrm{m}$ ( $8 \%$ of the manufacturer specified wall thickness). It is clear if we do not account for the phase effects the dimensional measurements can be off by a considerable amount, in this case $30 \mu \mathrm{m}$, when we need $\mu \mathrm{m}$ accuracies.

For the copper and gold tubes the outer-diameter micrometer and CT measurements track, but there is discrepancy with the manufacturer specifications. On average the measured $\mathrm{Cu}$ and $\mathrm{Au}$ tubes outer diameter and wall thicknesses are $\sim 20$ and $\sim 10 \%$ smaller than the manufacturer's values, repectively. The uncertainty in the wallthickness measurements for the copper and gold tubes reflects the variation on the inner edge of these tubes. In both of these cases there are very few phase effects in the DR or CT data.

The discrepancies between the micrometer and $\mathrm{CT}$ measurements and the manufacturer specifications reveal the difficulty in getting good phantoms/standards to perform actual measurements and for benchmarking x-ray digital radiography and computed tomography systems.

\section{References}

Logan, C., A. Waters, and H. Martz, (2004) “Edges for Digital Radiography \& NIF HEDP Capsule Phantoms for Computed Tomography", Lawrence Livermore National Laboratory, Livermore CA UCRL-ABS-207064. 


\section{Appendix \\ Wall Thickness calculations}

Wall thicknesses were calculated using the dimensional measurement tools in the internally developed 'imgrec' code. Two particular tools are important, the line tool, and the automated thickness tool for circular objects. The line tool works in two ways, the user draws a line spanning the feature and the code reports the number of pixels, and the physical distance (pixel distance * physical pixel size). Second, the user draws a line with space on both sides of the wall, and a wall thickness is calculated [Bossi, et al. 2002]. In the more automated tool a series of lines are drawn using the outer surface of the circular object and the center for the equations of the lines, and the wall thickness calculation is performed for each of these lines. The user provides a threshold and a width for bounding the size of the lines. The sequence of calculated thicknesses are generated as a vector (the results are plotted Figures 3-5). If noise becomes a concern, a segmentation routine is used to pre-process the CT reconstructed image before automated wall-thicknesses are calculated. In the case of the LDPE and the copper tubes the wall thicknesses were calculated with the un-segmented data. For the gold tube segmentation pre-processing was used to eliminate a few bad points in the image. However, the calculated thicknesses were compared with the un-segmented data in regions where the signal-to-noise was better and there was very little difference.

\section{Reference}

Bossi, Richard, Iddings Frank, Wheeler George C, and Patrick Moore, NonDestructive Testing Handbook, $3^{\text {rd }}$ Edition, Volume 4, Radiographic Testing, Chap13, 2002 ASNT. 